\title{
Prediction of Breakout Noise from a Rectangular Duct with Compliant Walls
}

\section{B. Venkatesham}

Department of Mechanical Engineering, Indian Institute of Technology, Hyderabad 502 205, India

\author{
Mayank Tiwari \\ GE India Technology Centre, Global Research, Whitefield Road, Bangalore 560 066, India
}

\author{
M. L. Munjal \\ Facility for Research in Technical Acoustics (FRITA), Department of Mechanical Engineering, Indian Institute of \\ Science, Bangalore-560012, India.
}

(Received 26 June 2010, accepted 31 May 2011)

Breakout noise from HVAC ducts is important at low frequencies, and the coupling between the acoustic waves and the structural waves plays a critical role in the prediction of the transverse transmission loss. This paper describes the analytical calculation of breakout noise by incorporating three-dimensional effects along with the acoustical and structural wave coupling phenomena. The first step in the breakout noise prediction is to calculate the inside duct pressure field and the normal duct wall vibration by using the solution of the governing differential equations in terms of Green's function. The resultant equations are rearranged in terms of impedance and mobility, which results in a compact matrix formulation. The Green's function selected for the current problem is the cavity Green's function with modification of wave number in the longitudinal direction in order to incorporate the terminal impedance. The second step is to calculate the radiated sound power from the compliant duct walls by means of an "equivalent unfolded plate" model. The transverse transmission loss from the duct walls is calculated using the ratio of the incident power due to surface source inside the duct to the acoustic power radiated from the compliant duct walls. Analytical results are validated with the FE-BE numerical models.

\begin{tabular}{|c|c|}
\hline$a_{n} \omega$ & $\begin{array}{l}\text { Complex amplitude of the nth acoustic pres- } \\
\text { sure mode }\end{array}$ \\
\hline$B_{m}(\omega)$ & Structural mode resonance term \\
\hline$b_{m}(\omega)$ & $\begin{array}{l}\text { Complex amplitude of the } \mathrm{m}^{\text {th }} \text { structural vibra- } \\
\text { tion velocity mode of the compliant wall }\end{array}$ \\
\hline$c_{0}$ & Speed of sound in air \\
\hline$C_{n, m}$ & $\begin{array}{l}\text { Coupling coefficient of the acoustic-structural } \\
\text { mode shape }\end{array}$ \\
\hline$D$ & Flexural rigidity \\
\hline$E$ & Young's modulus \\
\hline$f(\mathbf{z}, \omega)$ & $\begin{array}{l}\text { External force distribution on the surface of the } \\
\text { plate }\end{array}$ \\
\hline$h$ & Thickness of the duct wall \\
\hline$H()$. & Heaviside function \\
\hline$k=\omega / c_{0}$ & Acoustic wave number \\
\hline$L$ & Perimeter of the duct wall \\
\hline$L_{1}, L_{2}, L_{3}$ & $\begin{array}{l}\text { Dimensions of the acoustic subsystem in the } \\
x_{1}, x_{2} \text { and } x_{3} \text { coordinate directions, respec- } \\
\text { tively }\end{array}$ \\
\hline$m_{1}, m_{2}$ & Structural mode numbers with positive integers \\
\hline$n_{1}, n_{2}, n_{3}$ & Acoustic mode number integers \\
\hline$p(\mathbf{z}, \omega)$ & $\begin{array}{l}\text { Acoustic pressure inside the acoustic system as } \\
\text { function of location and frequency }\end{array}$ \\
\hline$p(\vec{x})$ & $\begin{array}{l}\text { The sound pressure inside the acoustic subsys- } \\
\text { tem as function of position vector }\end{array}$ \\
\hline$q_{n}$ & Generalized acoustic source strength \\
\hline
\end{tabular}

\section{NOMENCLATURE} tem structure

\begin{tabular}{l}
{$\left[\mathbf{Y}_{\mathbf{s}}\right]$} \\
$\Lambda_{n}$ \\
$\mathbf{a}$ \\
$\mathbf{b}$ \\
$\mathbf{g}_{\mathbf{a}}$ \\
$\mathbf{g}$ \\
$\mathbf{q}$ \\
$\mathbf{q}$ \\
$\nu$ \\
$\omega$ \\
$\omega_{n}, \zeta_{n}$ \\
$\bar{\Psi}_{n}(\mathbf{x})$ \\
$\phi_{m}(\mathbf{z})$ \\
$\Psi_{n}(\mathbf{x})$ \\
$\rho_{0}$ \\
$\rho_{S}$ \\
$\zeta$ \\
$a_{1}, b_{1}$ \\
$A_{m 1 m 2}$ \\
\hline
\end{tabular}

Uncoupled structural modal mobility matrix Normalization factor

Modal acoustic pressure vector

Modal vibration amplitude vector

Modal force vector acting on the acoustic sys-

Generalized modal force vector due to the external force distribution

Modal source vector due to vibration of the

N-length modal source strength vector

Poisson's ratio

Exciting frequency

Natural frequency and damping ratio of the nth acoustic mode, respectively

Orthonormal function

Uncoupled vibration mode shape function

Uncoupled acoustic mode shape function

Density of air

Density of the duct wall material or the structural subsystem

Transverse wall displacement

Dimensions of hypothetical piston

Eigen expansion function
$B_{m}(\omega)$

$c_{0}$

$D$

$$
E
$$

